\title{
TWO NEW GENERA OF ANTS FROM AUSTRALIA AND THE PHILIPPINES
}

\section{By WiLliam MoRToN WheEleR ${ }^{1}$}

Chapmanella gen. nov.

Worker: Integument rather thin, smooth and hairy. Head elongate, high in the frontal region, depressed and narrowed behind, without posterior corners. Eyes very small but distinct, placed well up on the dorsal surface near the middle of the sides. Ocelli absent. Mandibles narrow, decussating, with oblique, dentate apical borders. Clypeus rather large, not extending back between the frontal carinæ, which are very short, poorly developed and not very far apart. Frontal area and groove absent. Palpi short, the labial pair 4-jointed, the maxillary pair apparently 6-jointed, with the terminal joint much shorter than either of the two subequal preceding joints. Antennæ very long and slender, 12-jointed, inserted near the posterior corners of the clypeus; funiculus filiform, scarcely thickened apically. Antennal and clypeal foveæ not confluent. Thorax long and slender, with distinct promesonotal and mesoëpinotal sutures. Anterior portion of mesonotum narrow and subcylindrical; mesosterna convex and somewhat swollen anteriorly. Metanotal spiracles prominent, closely approximated, on the dorsal surface just anterior to the base of the epinotum, which is small, short and unarmed, with its spiracles situated on each side at the angle between the base and declivity. Petiole small and elongate, with a low, erect node at its anterior end. Gaster moderately large, with short first segment, which is convex anteriorly but does not overlie the petiole. Legs

${ }^{1}$ Contribution from the Entomological Laboratory of the Bussey Institution, Harvard University, No. 333. 
very long and slender; middle and hind tibiæ without spurs; tarsal claws slender and simple.

Genotype: Chapmanella negrosensis sp. nov.

Chapmanella negrosensis sp. nov.

Worker.-Length $4 \mathrm{~mm}$.

Head longer than broad, subelliptical, broadest through the middle where the small eyes, consisting of only about 16

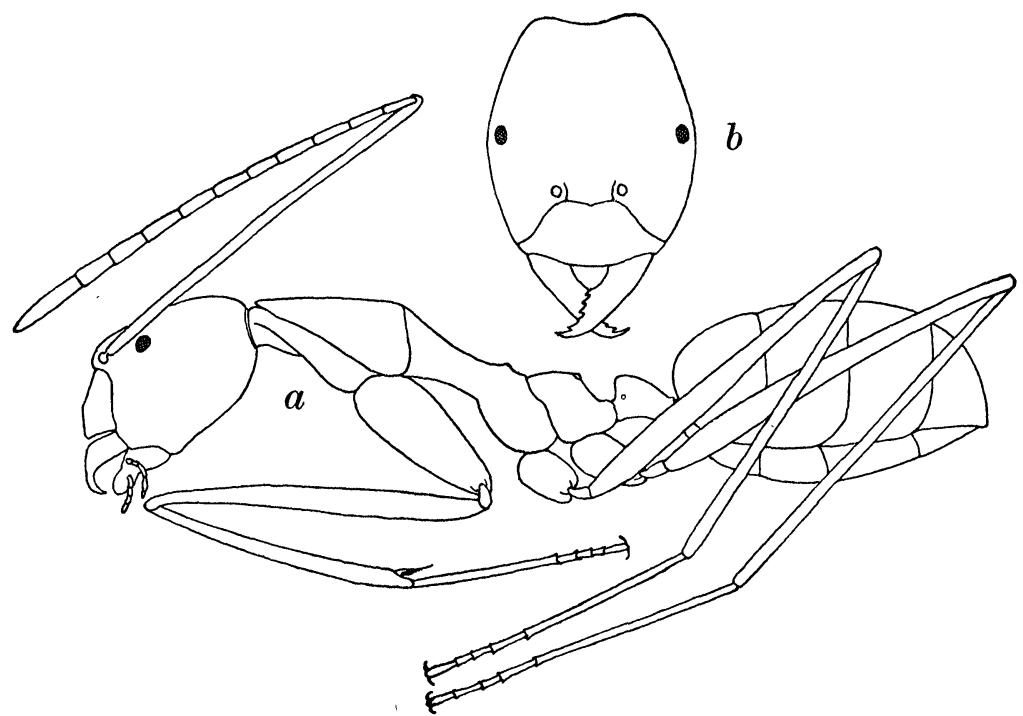

Fig. 1. Chapmanella negrosensis gen. et sp. nov. a, Worker, in profile; $b$, head of same, dorsal view.

ommatidia, are situated, the occipital border concave. Antennal scapes straight, extending more than half their length beyond the occipital border; all the joints of the funiculus except the last, subequal, nearly three times as long as broad, the last joint somewhat pointed, as long as the two penultimate joints together. Mandibles 6-toothed, the terminal tooth long and curved, the remaining teeth 
oblique, subequal, except the third from the apex, which is distinctly smaller. Clypeus convex, bluntly subcarinate in the middle, its anterior border broadly rounded and entire. Pronotum from above elliptical, one and one-half times as long as broad, with evenly rounded sides, its dorsal outline in profile nearly straight and horizontal. Mesonotum as long as the pronotum, its subcylindrical anterior portion long, slightly concave laterally, dorsally and ventrally, descending to the posterior portion which embraces the sides of the epinotum. The projecting metanotal spiracles interrupt the dorsal outline near its posterior end. Mesoëpinotal constriction short and feeble. Epinotum broader than long, in profile with straight base and declivity, meeting at an obtuse angle. Petiole longer than broad, broader in front than behind, the node in profile perpendicularly truncated anteriorly, rounded above, with its posterior surface gradually descending with even convexity to the posterior end of the segment. Legs very long and slender.

Smooth and shining; body, scapes and legs very delicately and indistinctly shagreened, with sparse piligerous punctures; mandibles less shining, very finely punctate-striate.

Pilosity yellowish, bristly, of uneven length, erect and moderately abundant, long on the body, shorter and more oblique but coarse also on the scapes and legs. Pubescence undeveloped.

Yellow, the legs and antennæ scarcely paler; mandibles more reddish with black teeth.

Described from a single specimen taken by Dr. J. W. Chapman, April 7, 1927, at Dumaguete Negros Oriental, Philippine Islands. This specimen, which superficially resembles an Anoplolepis longipes Jerdon, formed a portion of the prey captured by an army of Enictus læviceps F. Smith. The remainder of the prey comprised a worker of Ischnomyrmex longipes F. Smith, and two workers and several larvæ of Polyrhachis (Myrma) mayri Roger. The head of the Chapmanella had been crushed and the tip of its gaster bitten off by its captors, so that the conformation of these regions may be inaccurately represented in the figure.

The genus Chapmanella appears to be most closely related 
to Prenolepis and Paratrechina, as redefined by Emery, but is peculiar in the vary small size of the eyes, the short palpi, the unmodified base of the gaster, the shape of the petiole, the extremely long appendages and the absence of spurs on the middle and hind tibiæ. The pale color, small eyes, very long appendages and long pilosity of this ant indicate that it must be hypogaeic in habit. This might explain why it has not been taken heretofore and why the AEnicti, which forage more or less subterraneously, were able to reveal its existence.

The following is another undescribed genus belonging to the same tribe (Lasiini) of the subfamily Formicinæ.

\section{Aphantolepis gen. nov.}

Worker: Resembling Prenolepis in the structure of the head, thorax and gaster, but with somewhat harder integument. Eyes of moderate size; ocelli absent. Mandibles small, triangular, decussating, with finely dentate apical borders. Clypeus short, not extending back between the frontal carinæ, which are distinct, subparallel and as far apart as their distance from the lateral borders of the head. Frontal area and groove obsolete. Antennæ rather stout, 12-jointed, the funiculi but slightly enlarged towards their tips. Antennal and clypeal foveæ confluent. Palpi long, maxillary pair 6-jointed, with thickened basal and elongate terminal joint; labial pair 4-jointed. Thorax with deep mesoëpinotal constriction, dorsally approximated and protruding spiracles and prominent, highly placed epinotal spiracles. Petiole flattened above, without a node. Gaster rather large, its first segment truncated anteriorly and in life evidently overlying the petiole. Middle and hind tibiæ with well-developed spurs; tarsal claws simple.

Genotype: Aphantolepis quadricolor sp. nov.

Aphantolepis quadricolor sp. nov.

Worker-Length $2.7 \mathrm{~mm}$.

Head slightly longer than broad, distinctly narrowed anteriorly, with broadly rounded posterior corners and en- 
tire posterior border. Eyes moderately large and convex, placed a little in front of the middle of the sides of the head. Surface of clypeus rather flat, slightly projecting but scarcely subcarinate in the middle, the anterior border transverse, feebly sinuate on each side. Mandibles with nearly straight external and somewhat oblique apical bor-

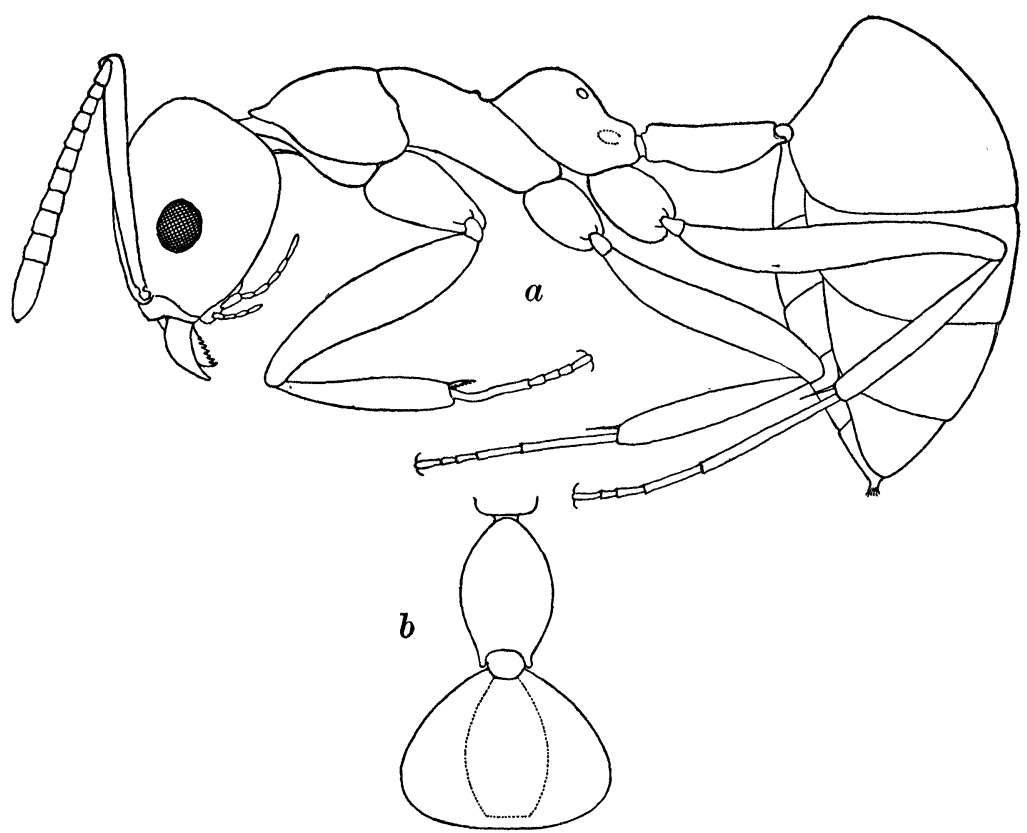

Fig. 2. Aphantolepis quadricolor gen. et sp. nov. a, Worker, in profile; $b$, petiole and anterior portion of first gastric segment, dorsal view.

ders, the latter with seven small, acute teeth, which are somewhat crowded and subequal, except the basal and third tooth from the apex, which are smaller. Antennal scapes extending nearly one-third their length beyond the posterior border of the head; first funicular joint twice as long as broad, nearly as long as the two succeeding joints together; joints 2-10 only slightly longer than broad, the terminal joint as long as the two penultimate joints together. Pro- 
notum from above trapezoidal, broader than long, broader anteriorly than posteriorly, in profile feebly convex above. Mesonotum much narrower than the pronotum, slightly longer than broad, as broad in front as behind, with subparallel, slightly concave sides, in profile rounded and sloping backward to the pronounced mesoëpinotal constriction. Epinotum broader than long, subrectangular from above, slightly broader behind through the prominent spiracles than in front; in profile with very convex, rounded base passing without an angle into the shorter, concave declivity. Petiole small, nearly twice as long as broad, from above regulariy elliptical, except at the posterior border where it is excised for the articulation of the gaster. A very feeble trace of the absent node is represented by the narrowly rounded anterior end of the flat dorsal surface; the ventral surface is distinctly convex. Gaster broad anteriorly, rapidly tapering and pointed posteriorly, the anterior truncated surface of the first segment longitudinally impressed in the middle for the accommodation of the petiole. Legs rather stout.

Smooth and shining, especially the dorsal surface of the head, the pronotum and the gaster, meso- and epinotum more subopaque, very finely and densely punctate or reticulate. Mandibles smooth, with a few scattered piligerous punctures.

Erect hairs brownish, pointed, few in number, of unequal length, arranged as pairs of macrochætæ on the head, proand mesonotum as in some species of Paratrechina (subgen. Nylanderia). Gaster both dorsally and ventrally with similar but shorter hairs, and the head and gaster also with more numerous short, suberect hairs or coarse pubescence. Antennal scapes and legs with pale, long, oblique, rather abundant pubescence.

Head and thorax yellowish red, the former a little darker, with a fuscous cloud on the vertex. Manibles, petiole, legs, scapes and first funicular joint clear yellow; remaining funicular joints dark brown; mandibular teeth and gaster black; terminal tarsal joints reddish.

Described from a single specimen taken by Mr. A. M. Lea in the Cairns District, Queensland, Australia, "among fallen leaves." 
This beautiful little ant may be readily recognized by its very peculiar nodeless petiole, which is unlike that of any known Formicid. In other respects it very closely resembles certain species of Prenolepis and Paratrechina (of the subgen. Euprenolepis). Until the female and male have been discovered it will be difficult to decide whether Aphantolepis is to be regarded as an independent genus or as a subgenus of Paratrechina. 

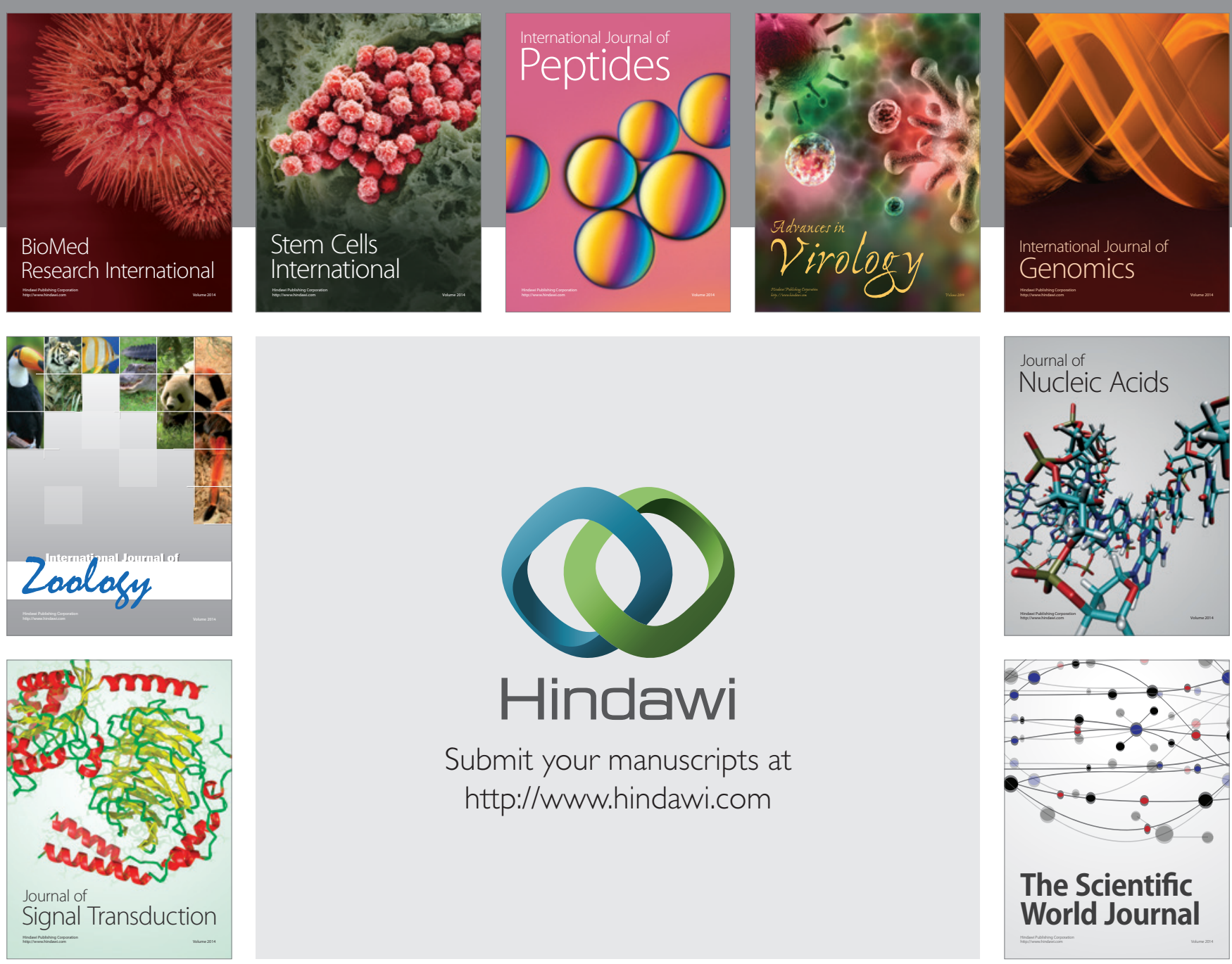

Submit your manuscripts at

http://www.hindawi.com
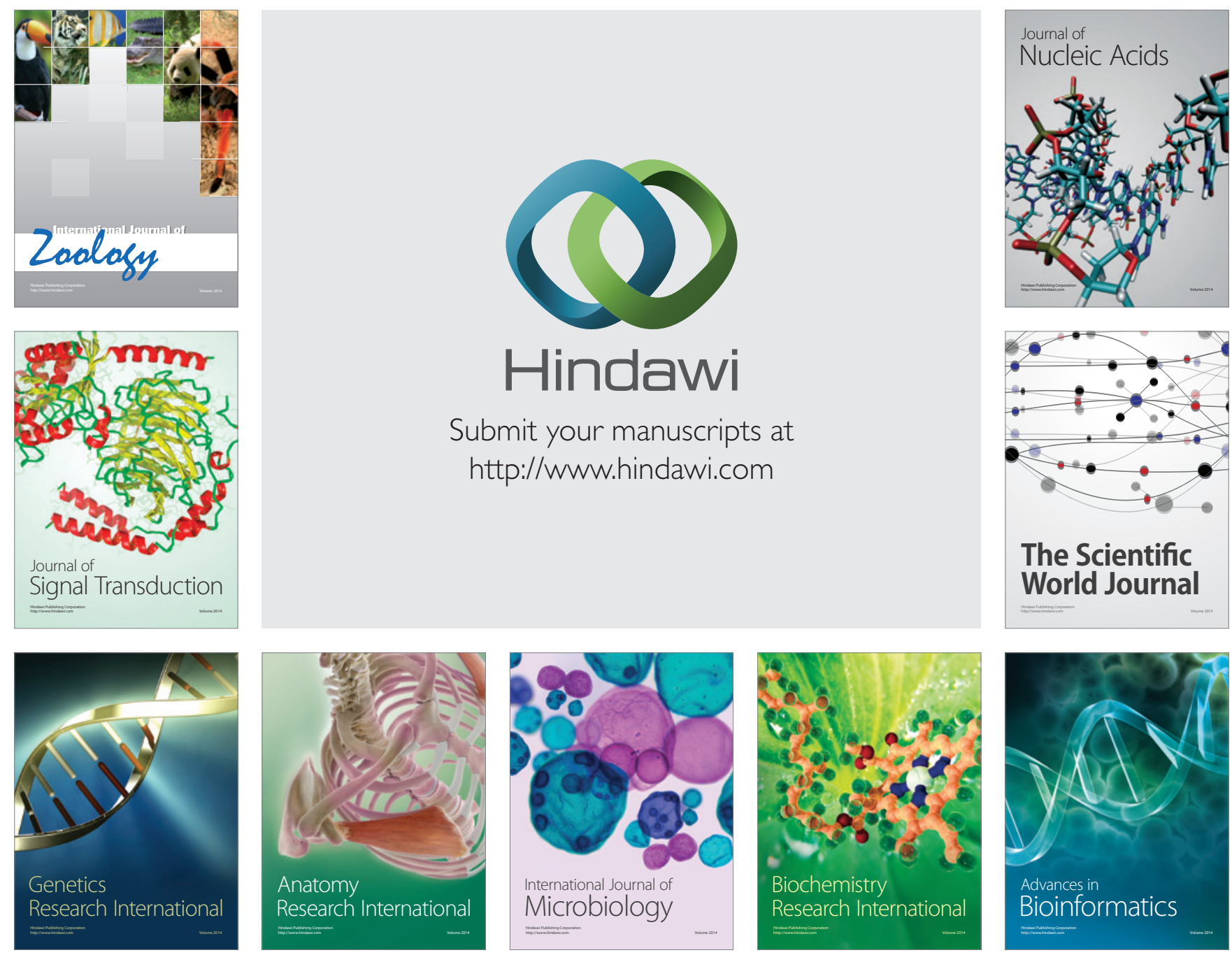

The Scientific World Journal
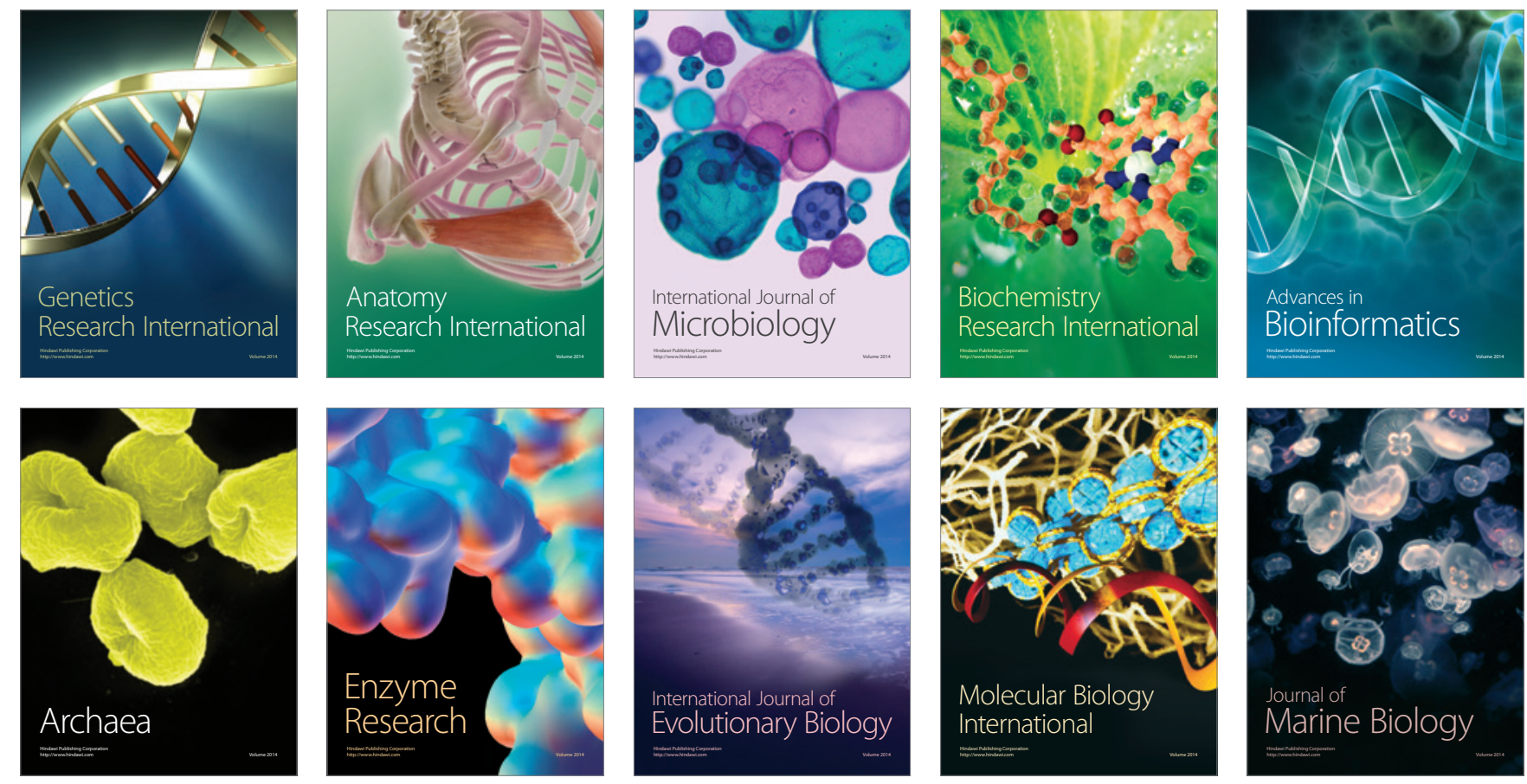